\title{
A REAL-WORLD ENERGY AND COST COMPARISON BETWEEN AN ELECTRIC VEHICLE AND A PETROL VEHICLE IN THE TRINIDAD AND TOBAGO CONTEXT
}

\author{
Bhopendra S. Maharaj ${ }^{1 *}$ and Graham King ${ }^{2}$ \\ ${ }^{1,2}$ Faculty of Engineering, The University of the West Indies, Trinidad \\ ${ }^{1}$ Email: bhopendra.maharaj@my.uwi.edu \\ ${ }^{2}$ Email: graham.king@sta.uwi.edu*(Corresponding author)
}

\begin{abstract}
This paper compares actual and predicted energy use and running costs for an internal combustion engine vehicle (ICE) and an electric vehicle (EV) in typical Trinidad and Tobago driving conditions. Detailed fuel/energy flow data were extracted to parameterise and validate representative MATLAB/Simulink models of each. Simulations were performed using a representative driving cycle as an input for both vehicle models and parameters such as fuel flow rate and rate of energy transfer were recorded. Energy used by the EV over the driving cycle was approximately $20 \%$ of that used by the ICE. The analysis was extended to consider the Well to Wheel energy use and $\mathrm{CO} 2$ emissions by combining the model results with published data, showing that both energy and $\mathrm{CO} 2$ emissions from the EV are approximately $50 \%$ of those produced by the ICE. Further, it was estimated based on the findings that if $10 \%$ of the vehicle fleet was displaced by EVs, this would provide a $9 \%$ contribution to the Trinidad and Tobago Paris Agreement Nationally Determined Contribution (NDC) for transportation by 2030. This could be significantly increased if renewable generating sources were to be added to the electrical grid.
\end{abstract}

Keywords: Electric vehicles, MATLAB/Simulink modelling, energy analysis, emission research, comparative study.

\section{https://doi.org/10.47412/ANEP5378}

\section{Introduction}

This paper aims to assess the potential energy and $\mathrm{CO} 2$ benefits of increasing the proportion of plug-in electric vehicles (EVs) and conventional petrol vehicles in Trinidad and Tobago. The transport sector of Trinidad and Tobago has historically been dominated by oil-based fuels. In recent years, there have been incentives that have encouraged a small penetration of CNG vehicles and hybrid vehicles. However, worldwide, electric vehicle transportation has become increasing popular. This research seeks to ascertain whether electric passenger vehicles are viable in Trinidad and Tobago, using similar approaches to other authors [1].

On the global stage, concerns about sustainable oil supply and greenhouse gas emissions is engendering increased adoption of hybrid vehicles and EVs and the automotive and oil industry is responding to this potential threat [2]. Many new EV and Hybrid models are being introduced by 
major automotive manufacturers and start-up companies alike. Counteracting this trend, since transportation is a key facilitator of economic development and societal expansion, as well as a product of it, there is in fact a rise in gasoline usage [3]. This is despite energy security, climate change and air quality fears.

The primary pollutant emissions from gasoline IC vehicles are carbon monoxide $(\mathrm{CO})$, nitrogen oxides (NOx) and unburnt hydrocarbons (HC) in the tailpipe [4]. When a gasoline engine uses a fuel-rich mixture, it propagates a larger amount of carbon monoxide emission [5]. Meanwhile, oxides of nitrogen are created at high temperatures during the combustion of the fuel-air mixture. In current gasoline vehicles, a catalyst cuts the emissions of the three gases by a factor of ten before leaving the exhaust [5]. Emissions from spark-ignition engines might be further decreased through variations in engine construction, combustion settings, and catalytic treatment [4].

EVs are propelled by electric motors and have energy storage in the form of one or more of: fuel cells; chemical batteries, ultracapacitors; and flywheels [6]. Currently, there are three main categories of electric vehicles. Hybrid Electric Vehicle (HEV), Battery Electric Vehicle (BEV) and Plug-In Hybrid Electric Vehicle (PHEV). An HEV has a drivetrain like an EV, with a combustion engine of some kind that can recharge the batteries intermittently. BEVs are exclusively powered by electricity, therefore, it does not require an internal combustion engine. PHEV contain both electric and combustion engines with batteries charged from the mains [7]. BEV batteries are currently usually charged from the grid.

Although EVs can yield a significant decrease in petroleum usage, they can actually result in an increase in $\mathrm{CO} 2$ emissions compared with IC vehicles if a high proportion of grid power is generated from coal, such as in the case of China [8]. Increased penetration of renewable energy on the grid, however, creates the possibility of significant reductions in $\mathrm{CO} 2$ from transportation if BEVs or PHEVs are deployed [9].

There are a few potential drawbacks to EVs. The demand for raw materials for batteries may create unintended, hidden, environmental consequences associated with mining [10]. At the end of the life of the battery, disposal creates environmental risks. Increased electricity grid demand may result in the generation of additional pollution or eco-unfriendly land use patterns. From an enduser point of view, the restricted range of EVs is the main obstacle to electrification in the car industry [2], which can lead to 'Range Anxiety' when the driver is concerned that the vehicle might not have enough stored energy to reach its destination. An added user anxiety is battery recharge time [1,11]. Nevertheless, Sierzchula et al. (2014) also recognizes that the cost of EVs, largely driven by battery prices, have persisted as being the most important obstacle to prevalent EV usage [11].

On balance, EVs have become a feasible alternative to IC vehicles [2][1] and have started to gain market share, especially locations such as Norway, China and California [12]. EVs coupled with low carbon electricity sources create the possibility for decreasing greenhouse gas discharges as well as eliminating tailpipe emissions [3][1]. 
Constant evaluations of emerging technologies such as EVs and their potential benefits over conventional alternatives are essential to provide comprehensive research and steer policy development. Trinidad and Tobago is no exception and we seek to contribute in this work.

Trinidad and Tobago has demanding driving conditions that can significantly compromise vehicle energy efficiency. It has a high humidity, tropical climate with maximum daily temperatures in the range of $30-35^{\circ} \mathrm{C}$ year-round. The national vehicle fleet is relatively large, with over 700,000 registered vehicles for a population of 1.4 million (around 500 vehicles/1000 people ranked about $30^{\text {th }}$ in the world on this metric) and a land area of $5,131 \mathrm{~km}^{2}$. A poorly planned road network leads to problematic traffic congestion, further exacerbating the roadway heat. This causes a high air conditioning load and start/stop driving with aggressive accelerations. The road surface is poor in places, requiring vehicles to further modulate their speed. Journey distances are often short, and the population underserved by its public transportation service. These conditions combine to create an environment which poor fuel efficiency, high exhaust emissions and air pollution along the arteries.

\section{Methodology}

Quantitative and qualitative methods are used in this research, and mostly primary sources of data for analysis. Real-world driving data from an EV and an equivalent ICE vehicle and were gathered to investigate differences in $\mathrm{CO} 2$ emissions and energy use in the context of Trinidad and Tobago. MATLAB and Simulink were used to generate models of both powertrains. A transient real-world driving cycle derived from empirical work in Trinidad and Tobago (the TTDC) was used as the input to the models. A questionnaire, aimed at understanding the driving population habits, was administered to seventy-five drivers with a response rate of $45 \%$.

\subsection{Vehicle Selection for Comparison}

Direct comparison of the ICE and EV vehicles requires that they bear some similar characteristics such as functionality, passenger and cargo space, external dimensions, vehicle mass, energy storage, aerodynamics, power, range and achievable speeds [13]. The Hyundai Ioniq Electric is the only currently available new EV on the market in Trinidad and Tobago. A feasible gasoline vehicle was selected that closely matched the characteristics of the Ioniq Electric and would be considered a competitor, a Hyundai Elantra. Comparative data is shown in Table 7.

Table 7: Vehicle parametric data

\begin{tabular}{|l|c|c|}
\hline & Hyundai Elantra ICE & Hyundai Ioniq EV \\
\hline Model Year & 2014 & 2018 \\
\hline Mass & 1267 & 1470 \\
\hline Engine Power $(\mathrm{kW})$ & 97 & 88 \\
\hline Transmission & 6-Speed Automatic & $\begin{array}{c}\text { Single Speed Reduction } \\
\text { Gear }\end{array}$ \\
\hline Frontal Area $\left(\mathrm{m}^{2}\right)$ & 2.03 & 2.11 \\
\hline Energy Storage $(\mathrm{kWh})$ & 431 & 28 \\
\hline
\end{tabular}




\begin{tabular}{|l|c|c|}
\hline $\begin{array}{l}\text { Approx. Driving Range } \\
(\mathrm{km})\end{array}$ & 615 & 200 \\
\hline Maximum Speed $(\mathrm{km} / \mathrm{h})$ & 195 & 165 \\
\hline Acceleration $(0-100 \mathrm{~km} / \mathrm{h})$ & 11.6 & 10.8 \\
\hline
\end{tabular}

\subsection{Drive Cycle Development}

A planned route of approximately $102 \mathrm{~km}$ was used for gathering data which incorporated North, Central and South, three main parts of Trinidad's geography. This allowed road gradient, average traffic and other related parameters were kept constant for the comparison between the vehicles.

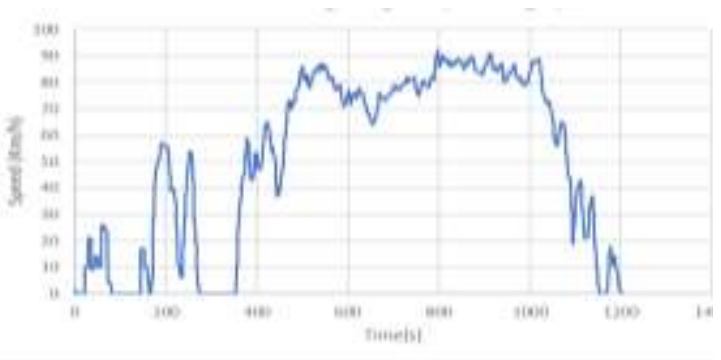

Figure 27: The Trinidad \& Tobago drive cycle highway (TTDC)

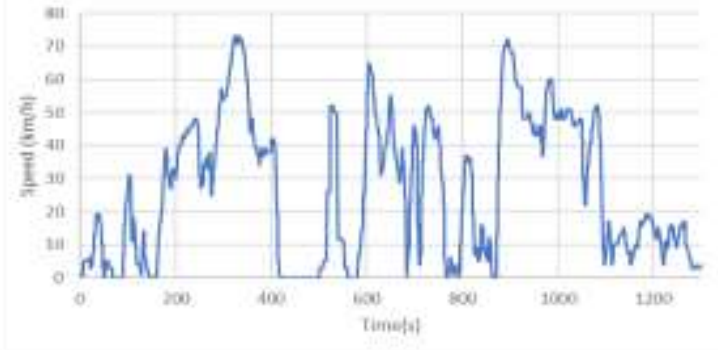

Figure 28: The Trinidad and Tobago suburban driving cycle (TTDC)

Established methods for post-processing of real-world driving data by classifying trips by routetype and defining micro-trips within each route type were deployed [14]. Synthesised Highway and Sub-Urban Trinidad and Tobago Drive Cycles (TTDC) were then created by combining a random selection micro-trips to meet a duration of about twenty minutes (Figure 27 and Figure 28). The total distance of the Highway cycle is $17.1 \mathrm{~km}$ and the average velocity is $51.1 \mathrm{~km} / \mathrm{h}$. The total distance of the Sub-Urban cycle is $9.7 \mathrm{~km}$ and the average velocity is $25.2 \mathrm{~km} / \mathrm{h}$.

\subsection{Data Collection for ICEV and BEV}

Both vehicles were inspected for defects, fault codes and any relevant parameter that would skew the data. The instrument used for all data collection in this project was an OBD adapter. A smart tablet was equipped with an application which received the signals from the OBD adapter, which allowed velocity time profiles and other vehicle parameters to be logged.

At the start of each trip, the test vehicle was started, the climate control was set at 'auto' 22 degrees Celsius and the application log recorder was started. The experiments were done at the same times during the week at 9:30 AM ET with two passengers. The ambient temperature of the environment and its conditions were noted each time. Three separate drive options were tested and recorded on the Ioniq EV which included: Normal, Eco and Sport mode. In total, nine drive cycles were recorded: six with the EV and three with the ICE vehicle. The data logged was retrieved from the tablet via csv files and processed in Microsoft Excel. Three additional drive cycles were recorded with the ICE vehicle, using a different route, for the purpose of model validation. 


\subsection{Model Development}

Modeling is the method of constructing a representation of some system of interest. The model must be a close estimate to the real system without being too complex for testing and experimentations. Models of both the EV and ICE vehicle are required and have been created using MATLAB/Simulink and its Powertrain Blockset, allowing the vehicle characteristics to be simulated over any drive cycle for energy consumption and emissions.

Parameterisation of the model required a focus on those parameters that have the greatest impact on energy consumption of the two vehicles, these being: gross vehicle weight; coefficients of drag and rolling resistance; environmental conditions; engine torque curve (ICE); gearing and efficiencies; fuel data; instantaneous torque output; battery charge/discharge rates (EV) and fuel flow (ICE); maximum battery capacity (EV) and fuel tank capacity (ICE).

\subsection{Model Validation}

The fuel economy of an ICE vehicle relates the distance moved by a vehicle and the amount of fuel consumed (liters/100km) or miles per gallon (MPG). Similarly, EV consumption relates the distance move to the amount of energy used (kilowatt hour/100miles) or miles per gallon equivalent (MPGe). The Environmental Protection Agency (EPA) imposes test drive cycles for a rated fuel or energy economy of a vehicle. Therefore, these rated values were compared to the modelled ones shown below. The modelled output unit for the ICE and EV were kilogram and watt used respectively from the scope shown.

'Cross Validation', was done which, required the reservation of a specific sample of a dataset which was not used in the modelling stages [17]. Several such samples were used with the real drive cycles for both vehicle models where the fuel flow rate and energy transferred rate respectively were recorded. These were compared with the same parameters logged during driving on a second-by-second basis. Error analysis using Root Mean Square Error (RMSE) methods as shown in Equation (1) provides a measure of model performance. Results of this detailed error analysis is presented in Table 9.

Table 18: Model validation results of ICE with NEDC and EV with FTP-75 and HWFET driving cycles $[15][16]$

\begin{tabular}{|l|l|l|l|l|l|}
\hline ICE & $\begin{array}{l}\text { L/100k } \\
\text { m }\end{array}$ & MPG & $\begin{array}{l}\text { Average of FTP-75 and } \\
\text { HWFET }\end{array}$ & MPGe & $\begin{array}{l}\text { kWh/100 } \\
\text { mi }\end{array}$ \\
\hline Rated & 7.8 & 30.16 & Rated & 136 & 25.045 \\
\hline Modelled & 6.92 & 33.99 & Modelled & 139.74 & 24.155 \\
\hline Error & \multicolumn{2}{|c|}{$11.28 \%$} & \multicolumn{3}{|c|}{$3.55 \%$} \\
\hline
\end{tabular}




$$
R M S E=\sqrt{\frac{1}{n} \sum_{i=1}^{n}\left(\text { Modelled }_{i}-\text { Actual }_{i}\right)^{2}}
$$

Table 9: Error Calculation for ICE and EV for model validation

\begin{tabular}{|l|c|c|c|c|c|c|}
\hline \multicolumn{2}{|l|}{ ICE (litres) } & \multicolumn{4}{l|}{ EV (kilowatts) } \\
\hline & Test 1 & Test 2 & Test 3 & Test 1 & Test 2 & Test 3 \\
\hline Actual & 1.1635 & 3.0973 & 2.0437 & 6.3783 & 7.0084 & 6.6097 \\
\hline RMSE & 0.00129 & 0.00085 & 0.00077 & 0.00761 & 0.011481 & 0.014345 \\
\hline Error & $0.11 \%$ & $0.027 \%$ & $0.038 \%$ & $0.119 \%$ & $0.164 \%$ & $0.217 \%$ \\
\hline
\end{tabular}

\subsection{Well-to-Wheel Analysis}

Well-To-Wheel Analysis (WTW), aims to accomplish a complete investigation of the total valuechain energy use of different types of vehicles using a levelled approach. The Well-to-Wheel (WTW) chain is made up of two stages, a Well-to-Tank (WTT) and Tank-to-Wheel (TTW) analysis. The energy cost of transmission or transportation of fuel to the refuelling or recharging point are considered in this method, as well as the efficiency of the use of the fuel in the vehicle. It accounts for upstream/downstream energy usage, air pollutants and GHG emissions throughout the value chain.

\section{Results and Analysis}

\subsection{Simulation and Real-World Test Results}

The output results of simulations for the ICE vehicle model using the previously derived Trinidad and Tobago Drive Cycle (TTDC) were plotted and shown below. Figure 29 and Figure 30 represent second-by-second fuel flow in the ICE vehicle. Figure 31 and Figure 32 represent second-bysecond energy transfer in the EV.

Real-world energy/fuel use from the direct comparison test are shown in The difference in Energy Usage between the ICE vehicle and EV in the Direct Comparison road test (Error! Not a valid bookmark self-reference.) and the Simulation test using the TTDC (Table 21) are very closely aligned. This lends confidence to the validity of the simulation method for representing energy use of both vehicles.

Table 20. The fuel flow rate $(1 / \mathrm{h})$ for the ICE vehicle and the instantaneous power $(\mathrm{kW})$ for the EV were logged. Fuel flow rate( $1 / \mathrm{h})$ was post-processed to obtain fuel used (l) and instant power $(\mathrm{kW})$ was post-processed to obtain energy used $(\mathrm{kWh})$ based on the standard conversion of $8.9 \mathrm{kWh}$ of energy per litre of gasoline. 


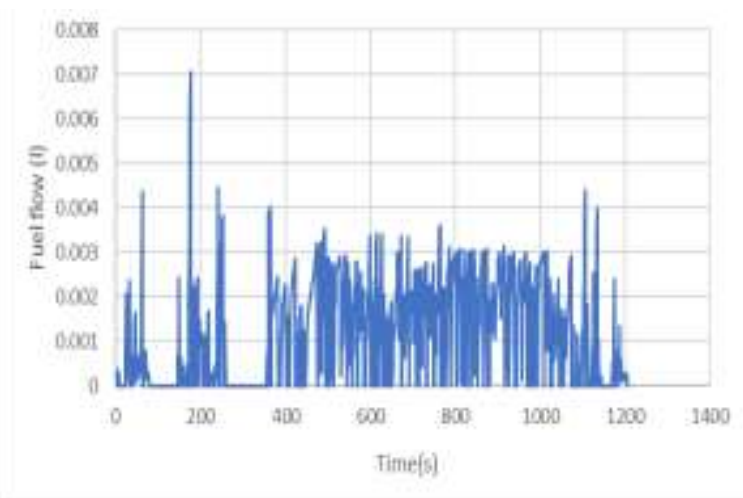

Figure 29: Simulated fuel flow rate for ICE TTDC highway

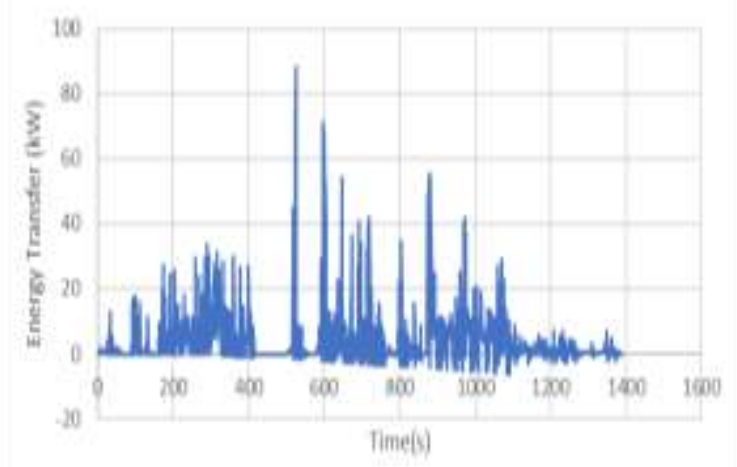

Figure 31: Simulated Energy Transfer for the EV Vehicle Model Under the TTDC Highway

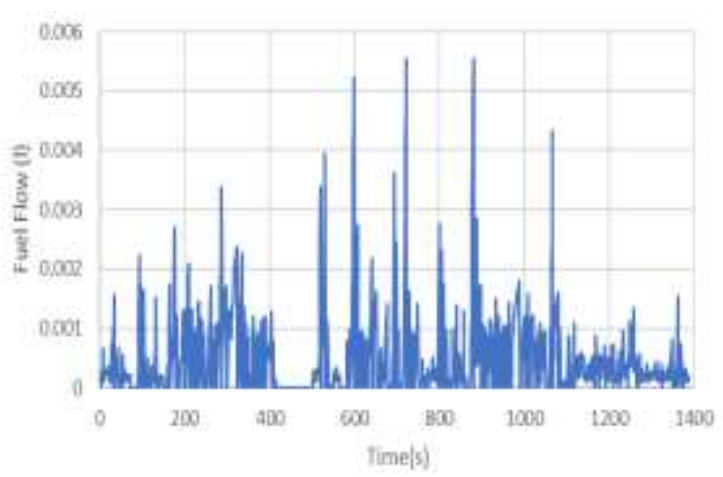

Figure 30: Simulated fuel flow rate for ICE TTDC sub-urban

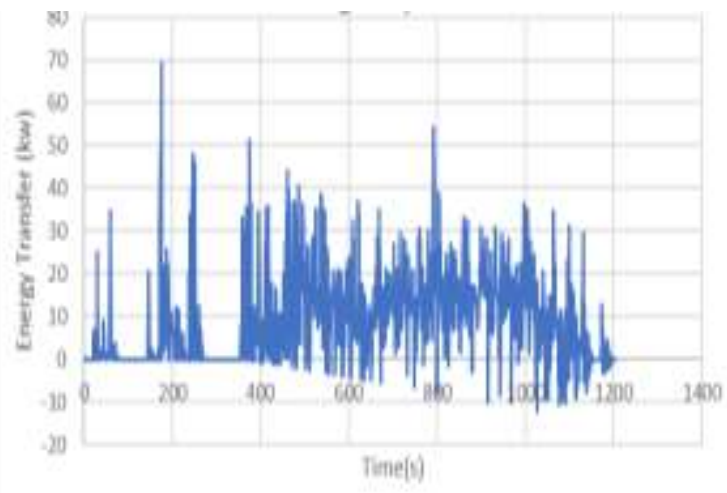

Figure 32: Simulated Energy Transfer the EV Vehicle Model Under the TTDC Sub-Urban

The output simulation results are summarized in Table 7Table 21. The difference in Energy Usage between the ICE vehicle and EV in the Direct Comparison road test (Error! Not a valid bookmark self-reference.) and the Simulation test using the TTDC (Table 21) are very closely aligned. This lends confidence to the validity of the simulation method for representing energy use of both vehicles. 
Table 20: Direct comparison tests for ICE and EV

\begin{tabular}{|l|c|c|}
\hline Test & ICE (litres) & EV (kWh) \\
\hline Test $\mathbf{1}$ & 3.8 & 6.2 \\
\hline Test 2 & 3.6 & 6.1 \\
\hline Average & 3.7 & 6.2 \\
\hline Average Energy Used (kWh) & 33.2 & 6.2 \\
\hline $\begin{array}{l}\text { Average Energy Difference } \\
\text { (kWh) }\end{array}$ & \multicolumn{2}{|c|}{$27.0(81.3 \%)$} \\
\hline
\end{tabular}

Table 21: Energy comparison for simulations with TTDC

\begin{tabular}{|l|c|c|}
\hline Drive Cycle & ICE (litres) & EV (kWh) \\
\hline TTDC Highway & 1.46 & 2.77 \\
\hline TTDC Sub-Urban & 0.72 & 1.1 \\
\hline Combined & 2.18 & 3.87 \\
\hline Energy Used (kWh) & 19.40 & 3.87 \\
\hline Vehicle Efficiency (kWh/km) & 0.72 & 0.14 \\
\hline $\begin{array}{l}\text { Energy Difference in Combined Cycle } \\
\text { (kWh) }\end{array}$ & \multicolumn{2}{|c|}{$15.53(80.1 \%)$} \\
\hline
\end{tabular}

\subsection{Electric Vehicle Driving Range in Trinidad and Tobago}

The selected EV has a battery capacity of $28 \mathrm{kWh}$ and the ICE vehicle has a fuel storage of 431 $\mathrm{kWh}$ (Table 7). Based on the findings of this study, driving on a representative Trinidad and Tobago Driving Cycle will consume $3.87 \mathrm{kWh}$ over the combined Highway and Sub-Urban TTDC. The combined distance of the two cycles is $26.8 \mathrm{~km}$. Therefore, the total estimated range of the two vehicles are:

$$
\begin{aligned}
& \operatorname{Range}_{E V}=\frac{26.8}{3.87} \times 28=193.9 \mathbf{k m} \\
& \text { Range }_{I C E}=\frac{26.8}{19.38} \times 431=596 \mathbf{~ k m}
\end{aligned}
$$

This result is very informative, as it shows that the expected range of an EV in Trinidad and Tobago is only slightly below its advertised range despite the rigorous environmental conditions. The range will allow for almost all daily two-way commutes, allowing for charging exclusively at home. This is significant in the absence of a fast charging infrastructure in the country. As expected, the range 
of the ICE over the TTDC is three times greater than that of the EV, but note that is achieved from 15.3 times greater energy storage capacity, due to the far greater efficiency of the EV.

\subsection{Well to Wheel Analysis}

Curran et al. (2014) use a method for Well to Wheel analysis for both EVs and ICEs which is used as the basis for this analysis [19]. However, the Tank to Wheel stage has been replaced with results from simulation of the TTDC.

Table 22: Well to Wheel Table Estimate with Combined TTDC Vehicle Usage

\begin{tabular}{|l|c|c|c|c|}
\hline $\begin{array}{l}\text { Vehicle Type/ } \\
\text { Mix }\end{array}$ & $\begin{array}{c}\text { Tank to Wheel } \\
\text { (kJ/km) }\end{array}$ & $\begin{array}{c}\text { Well to Wheel } \\
\text { (Total) }(\mathbf{k J / k m})\end{array}$ & $\begin{array}{c}\text { Tank to Wheel } \\
\text { GHG/CO2 } \\
(\mathbf{g} / \mathbf{k m})\end{array}$ & $\begin{array}{c}\text { Well to Wheel } \\
\text { GHG/CO2 } \\
\text { (g/km) }\end{array}$ \\
\hline ICE/ Crude Oil & 2599.14 & 3299.14 & 200.73 & 250.73 \\
\hline $\begin{array}{l}\text { EV/ Natural } \\
\text { Gas }\end{array}$ & 518.67 & 1718.67 & 0 & 130 \\
\hline EV Saving & 2080.47 & 1580.47 & 200.73 & 120.73 \\
\hline
\end{tabular}

Full Well-to-Wheel CO2 emissions of the EV is just over half that of the ICE vehicle in Trinidad and Tobago. Electricity generation in this territory at the time of writing is $100 \%$ Natural Gas fuelled using a combination of closed-cycle and open-cycle gas turbines.

\subsection{Emissions and the Paris Agreement}

Trinidad and Tobago has ratified the Paris Agreement and confirmed its Nationally Determined Contribution (NDC) which includes an unconditional reduction in public transportation emissions by $30 \%$ or $1.7 \mathrm{MtCO} 2 \mathrm{e}$ compared to 2013 levels by December 31, 2030. According to the Wellto-Wheel analysis in Table 22, introducing EVs, even with established fossil-fuel power generation, can offer a $48 \%$ reduction in $\mathrm{CO} 2$ per vehicle. By making some basic assumptions, the potential depth of impact of introducing EVs can be assessed.

Survey results indicated that the modal score was less than or equal to $330 \mathrm{~km}$ per week of driving, with the average found to be $342.3 \mathrm{~km}$ per week.

$$
\begin{gathered}
\text { Average Annual Household Mileage }=342.3 \times 52=17800 \mathrm{~km} \\
\text { Annual CO2 Savings per vehicle }=120.7 \times 17800=2.15 \text { tons CO2 }
\end{gathered}
$$

If $10 \%$ of the national vehicle fleet transitioned to EV by 2030 , approximately 70,000 EVs would have displaced ICE vehicles. This would save:

$$
\text { Annual CO2 Savings }=2.15 \times 70000=150,500 \text { tons }
$$

As a proportion of the NDC this contributes: 


$$
\text { Proportion of NDC }=\frac{150000}{1700000} \times 100=9 \%
$$

Clearly, this is a small but valuable percentage of the NDC. If the source of power generation was modified to incorporate additional renewable energy, or if efficiency of the natural gas power generation was improved, this figure would significantly increase due to reduced Well-to-Wheel $\mathrm{CO} 2$ emissions. In addition, the greatest impact of increasing the penetration of EVs will be on air quality, since they have zero tailpipe emissions.

\subsection{EV vs ICE Vehicle Cost of Ownership}

Net running costs of a vehicle can be taken as: Capital Depreciation + Energy Costs + Maintenance Cost. We can calculate the Total Cost of Ownership for the EV and the ICE vehicle, with the timeframe assumed to be 5 years and with similar usage in each case (Table 23). The maintenance cost estimations were derived from Lebeau et al. (2013) [20]. Please note that all costs are shown in TTD.

Although the energy and maintenance costs of the EV are significantly less than the ICE vehicle, this is somewhat offset by the higher anticipated depreciation and the higher initial purchase price. Nonetheless, the ultimate lifetime (5 year) Cost of Ownership of the EV is estimated in this analysis to be $8 \%$ less than that of the ICE vehicle.

\section{Conclusion}

Analysis of two comparable vehicles, an EV and a gasoline ICE, in typical driving conditions in Trinidad and Tobago, has shown that the EV is beneficial in most metrics. A MATLAB/Simulink

Table 23: Cost of Ownership Comparison ICE Vehicle vs EV

\begin{tabular}{|c|c|c|}
\hline Cost & ICE & EV \\
\hline Purchase Price & $\$ 229,000.00$ & $\$ 259,000.00$ \\
\hline 5-year Depreciation (approx.) ${ }^{1}$ & $45 \%$ & $50 \%$ \\
\hline Capital Depreciation [A] & $\$ 103,050.00$ & $\$ 129,500.00$ \\
\hline Energy Cost per kWh ${ }^{2}$ & $\$ 0.56$ & $\$ 0.37$ \\
\hline Average Annual Mileage & 17800 & 17800 \\
\hline TTDC Energy Efficiency (kWh/km) & 0.72 & 0.14 \\
\hline Total Energy Cost [B] & $\$ 35,784$ & $\$ 4,610$ \\
\hline Maintenance Cost per $\mathrm{km}^{3}$ & $\$ 0.25$ & $\$ 0.16$ \\
\hline Total Maintenance Cost [C] & $\$ 21,805.00$ & $\$ 14,151.00$ \\
\hline Cumulative Cost $[\mathrm{A}+\mathrm{B}+\mathrm{C}]$ & $\$ 160,639.00$ & $\$ 148,261.20$ \\
\hline Total Cost of Ownership per km & $\$ 1.80$ & $\$ 1.67$ \\
\hline
\end{tabular}

${ }^{1} \mathrm{~A}$ higher rate of depreciation is assumed for the EV given its higher purchase price and the rapid evolution of EV technology, which is assumed to have a negative effect

${ }^{2}$ Calculated based on a pump price of $\$ 4.97 /$ litre and the energy content of 1 litre of gasoline being $8.9 \mathrm{kWh}$

${ }^{3}$ Maintenance cost estimations were derived from Lebeau et al. (2013) [20] 
simulation model of each vehicle was created and validated with real-world data, proving that the models are representative. A Trinidad \& Tobago Drive Cycle was developed and used as the input to the simulation model. Results showed that Well-to-Wheel EV Energy Use and CO2 emissions are $52 \%$ of its ICE vehicle counterpart. This can be improved still further if, and when, a higher proportion of renewable energy feeds the electrical grid. If EVs penetrated $10 \%$ of the Trinidad and Tobago vehicle fleet by 2030, assuming that the source of grid power remains the same, they would contribute 3\% to the Trinidad and Tobago Paris Agreement NDC. Cost of ownership over a five-year period was compared and the EV proved to be approximately $8 \%$ cheaper. Therefore, the main contribution of EVs over ICE vehicles in a Trinidad and Tobago context are reduced CO 2 emissions and reduced air pollution due to the lack of tailpipe emissions.

\section{References}

[1] O. Van Vliet, A.S. Brouwer, T. Kuramochi, M. Van Den Broek, A. Faaij, Energy use, cost and CO2 emissions of electric cars, J. Power Sources. 196 (2011) 2298-2310. https://doi.org/10.1016/j.jpowsour.2010.09.119.

[2] R. van Haaren, Assessment of Electric Cars' Range Requirements and Usage Patterns based on Driving Behavior recorded in the National Household Travel Survey of 2009, 2011. http://legacy.veva.ca/papers/HowFarWeDrive_v1.2.pdf.

[3] T.R. Hawkins, B. Singh, G. Majeau-Bettez, A.H. Strømman, Comparative Environmental Life Cycle Assessment of Conventional and Electric Vehicles, J. Ind. Ecol. 17 (2013) 5364. https://doi.org/10.1111/j.1530-9290.2012.00532.x.

[4] A. Faiz, C.S. Weaver, M.P. Walsh, Air pollution from motor vehicles: standards and technologies for controlling emissions, Washington, DC, 1996. http://siteresources.worldbank.org/INTURBANTRANSPORT/Resources/b02airpolution.p df.

[5] E. Sher, Handbook of Air Pollution from Internal Combustion Engines, Boston Academic Press, 2011.

[6] M. Ehsani, Y. Gao, S. Longo, K. Ebrahimi, Modern Electric, Hybrid Electric, And Fuel Cell Vehicles, 2004.

[7] M. Palinski, A Comparison of Electric Vehicles and Conventional Automobiles : Costs and Quality Perspective, Yrkeshögskolan Novias, 2017. https://www.theseus.fi/bitstream/handle/10024/133032/BA.pdf?sequence=1\&isAllowed= $\mathrm{y}$.

[8] H. Huo, Q. Zhang, M.Q. Wang, D.G. Streets, K. He, Environmental implication of electric vehicles in china, Environ. Sci. Technol. 44 (2010) 4856-4861. https://doi.org/10.1021/es100520c.

[9] D.B. Richardson, Electric vehicles and the electric grid: A review of modeling approaches, Impacts, and renewable energy integration, Renew. Sustain. Energy Rev. 19 (2013) 247-254. https://doi.org/10.1016/j.rser.2012.11.042.

[10] D.A. Notter, M. Gauch, R. Widmer, P. Wäger, A. Stamp, R. Zah, H.J. Althaus, 
Contribution of li-ion batteries to the environmental impact of electric vehicles, Environ. Sci. Technol. 44 (2010) 7744. https://doi.org/10.1021/es1029156.

[11] W. Sierzchula, S. Bakker, K. Maat, B. Van Wee, The influence of financial incentives and other socio-economic factors on electric vehicle adoption, Energy Policy. 68 (2014) 183194. https://doi.org/10.1016/j.enpol.2014.01.043.

[12] IEA, Global EV Outlook 2019: Scaling up the transition to electric mobility, Paris, 2019. https://www.iea.org/reports/global-ev-outlook-2019.

[13] J. Martins, F.P. Brito, D. Pedrosa, V. Monteiro, J.L. Afonso, J. Martins, F.P. Brito, D. Pedrosa, V. Monteiro, Real-Life Comparison Between Diesel and Electric Car Energy Consumption, in: Grid Electrified Veh. Performance, Des. Environ. Impacts, Nova Science Publishers, New York, NY, USA, 2013: pp. 209-232. https://www.novapublishers.com/catalog/product_info.php?products_id=44945.

[14] W.T. Hung, H.Y. Tong, C.P. Lee, K. Ha, L.Y. Pao, Development of a practical driving cycle construction methodology: A case study in Hong Kong, Transp. Res. Part D Transp. Environ. 12 (2007) 115-128. https://doi.org/10.1016/J.TRD.2007.01.002.

[15] 2018 Hyundai Ioniq Electric MPG \& Gas Mileage Data, Edmunds. (2010). https://www.edmunds.com/hyundai/ioniq-electric/2018/mpg/ (accessed November 18, 2019).

[16] P. Zal, 2013 Hyundai Elantra 1.6 MPI, (n.d.). https://www.automobilecatalog.com/car/2013/1608905/hyundai_elantra_1_6_mpi.html (accessed November 18, 2019).

[17] S. Ray, Improve Your Model Performance using Cross Validation (in Python and R), Anal. Vidhya. (2018). https://www.analyticsvidhya.com/blog/2018/05/improve-modelperformance-cross-validation-in-python-r/ (accessed November 22, 2019).

[18] A.G. Simpson, Full-cycle assessment of alternative fuels for light-duty road vehicles in Australia, 2004. http://www.autospeed.com.au/static/downloads/articles/110155_UPDATED_FullCycle_Assessment_of_Alternative_Fuels_for_Light-

Duty_Road_Vehicles_in_Australia.pdf\%5Cnpapers2://publication/uuid/A4FDDED028F6-4887-9176-6E2881F66D3A.

[19] S.J. Curran, R.M. Wagner, R.L. Graves, M. Keller, J.B. Green, Well-to-wheel analysis of direct and indirect use of natural gas in passenger vehicles, Energy. 75 (2014) 194-203. https://doi.org/10.1016/j.energy.2014.07.035.

[20] K. Lebeau, P. Lebeau, C. Macharis, J. Van Mierlo, How expensive are electric vehicles? A total cost of ownership analysis, World Electr. Veh. J. 6 (2013) 996-1007. https://doi.org/10.3390/wevj6040996. 